\title{
So what's so special about these things called lampbrush chromosomes?
}

\author{
Herbert Macgregor
}

Published online: 14 December 2012

(C) Springer Science+Business Media Dordrecht 2012

We have known about lampbrush chromosomes for 130 years. They have been the subject of over 300 papers of which 63 have been published in the twentyfirst century. They have been described in the growing ovarian oocytes of 45 animal species from vertebrate and invertebrate phyla. There is no lampbrush stage in oogenesis of mammals but that is not to say that mammalian chromosomes are incapable of becoming lampbrushy. Just take a look at the paper by Liu and Gall in this issue: it's truly amazing!

The technologies applied to the study of lampbrush chromosomes (LBCs) range from the most basic, as seen in the pioneering works of Flemming in 1882 and Callan and Lloyd in the 1960s to the very frontiers of twentyfirst century science, as seen in most of the papers in this issue of Chromosome Research. The LBCs of amphibians and birds provide wonderful opportunities for visualising and exploring the intricacies of RNA transcription and processing and for deciphering the mechanics of chromatin: thousands of transcription units, packed to capacity with polymerases, major sartorial changes from compact metaphase to millimetre long LBCs, all visible with a light microscope and almost seemingly customised for modern cytomolecular research, a dynamic system offering a dazzling array of questions and challenges. Our papers from the labs of Joe Gall (Baltimore, USA), Michel Bellini (Urbana, Ill.), Garry Morgan (Nottingham, UK), Elena Gaginskaya and Alla Krasikova (St. Petersburg, Russia) and May

H. Macgregor $(\bowtie)$

School of Biosciences, University of Exeter,

Exeter, UK

e-mail: herbert.macgregor@btinternet.com
Penrad-Mobayed (Paris, France) are all examples of just how far you can push this exciting field.

So why is it that so many of today's young cell biologists have never even heard of LBCs and certainly never considered them as an appropriate model system for work on RNA transcription or chromatin or the molecular biology of oogenesis and early development? Why indeed!

The reasons are, I think, quite simple.

First, working with germinal vesicles and LBCs requires manual skill and this has to be painstakingly learned: no machines, no computers, no high-tech glamour-just sitting at a bench with a dissecting microscope and using some very fine forceps, needles and pipettes to do something that is, by any standards, quite hard. All this has to be taught by an expert, and there are currently about 10 experts in the world in half as many places. Yet, I used to teach practical lampbrushology to a class of 40 undergraduates at a British university and in just a few hours of trying at least $50 \%$ of them ended up with a nice preparation! So it can't be that difficult!

Secondly, microscopy. To work with LBCs you must have a good light microscope and you must know how to use it very critically. That's often a problem. At one time, the icon of a biologist was a person seated at a microscope. Today it's a person clad in a white coat and latex gloves holding an Eppendorf. But make no mistake, twenty-first century light microscopy is incredible fun and LBCs are beautiful to behold!

Then there are the animals. All but three of the 45 species that have had their LBCs investigated have to be caught in the wild and most are now protected by law. Many are unobtainable and some might even be extinct. 
The past endeavours of some biologists in search of rare lampbrush treasures in the most unlikely places easily rival the adventures of King Arthur in his quest for the Holy Grail! So the fact is that if you're not content to use Xenopus, axolotl or chicken, you're likely to have problems and you'll need to have an adventurous spirit.

And then, of course, there's the matter of funding. It's been the bitter experience of most lampbrushers that granting authorities are less than enthusiastic about work that is based on what happens in a frog's egg, even if the research promises breakthroughs that will impact widely across the field of cell science. But we keep on trying and, amazingly, we succeed; the quality and significance of the excellent research described in this issue bears witness.

I myself have not made a preparation of lampbrush chromosomes for 15 years. My involvement in the field is now from the touchline and at the promotional level. The players on the field are, with few exceptions, young, strong and completely dedicated to the "lampbrush cause". The most notable exception is, of course, Joe Gall, who published his first paper on LBCs in 1954 and has not only remained absolutely at the top of the field right through to the middle of his ninth decade, but has also trained and inspired countless others, including myself and many of the authors that feature in this special issue.

Modern science publishing and the revolution of open access has led scientists to search the Internet for specific papers that relate directly to their current research. Browsing has become difficult and unfashionable. We no longer reach for the latest copy of $J C B$ or Cell or Chromosome Research, make a cup of coffee, put our feet up and see what they have to offer. This journal launched its programme of special issues 10 years ago with the objective of giving our readers the chance to find out everything that's happening now and at the bench in specific fast moving fields of cell biology. In this sense, we hope that you will be motivated to browse through everything in this special issue and if, having done so, you have some good ideas, talk to us.

Finding out more about LBCs couldn't be easier. Everything about them is on our website http:// www.projects.exeter.ac.uk/lampbrush

After that, it's all about asking questions, designing experiments and having a go. 